\title{
Heading South
}

\author{
An Introduction
}

For over two centuries now, privileged northern European men have traveled to Mediterranean lands in search of male-male sex and love. Pushed by social rejection, scandal, and sometimes executions, and pulled by travelers' reports of more relaxed southern mores — and, ironically, by censorious descriptions of the acceptance of "unnatural vice" in Islamic lands-European men were drawn into a long conversation of acts and ideas.

Early twentieth-century German sexologist Iwan Bloch (1933, 3I) must have reflected popular opinion when he wrote: "It can, indeed, be due only to climatic conditions that today sexual perversions, especially homosexuality, are more deeprooted, more frequent, and much less severely judged by the public morality in southern Europe than in northern; that in fact there are great differences between northern and southern Italy in this respect."

Bloch seems to have been echoing Sir Richard Burton's late nineteenth-century creation of what the latter termed the Sotadic Zone- a band across the globe that extended from the 


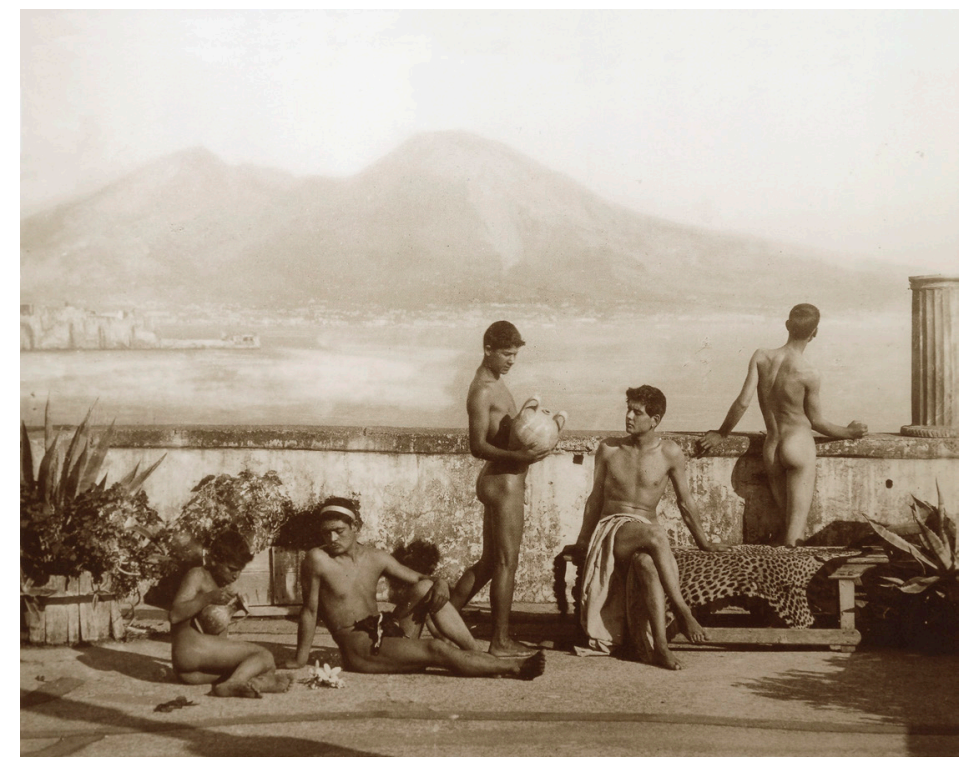

Figure I. Terra del fuoco (Land of Fire), by Baron Wilhelm von Gloeden. One of von Gloeden's most famous images, it captures Vesuvius from a terrace in Naples. The south is a land of warmth and pleasure in which unexpected desires can erupt.

Mediterranean eastward through the Middle East to China and Japan to the preconquest New World, in which, according to Burton, male same-sex sex was "popular and endemic, held at the worst to be a mere peccadillo, whilst the races to the North and South of its limits ... practice it only sporadically amid the opprobrium of their fellows who, as a rule, are physically incapable of performing the operation and look upon it with the liveliest disgust" (quoted in Bleys 1995, 217).

It was not, of course, that Mediterranean cultures were somehow "looser"; they were simply differently structured. ${ }^{2}$ Extending back to ancient Greece (Halperin 1990), what was prohibited for adult men was not simply other men but being penetrated by 
other men. Thus, it often appeared to upper-class northerners that virtually any Sicilian or Arab was available to them, but, of course, the terms of that availability were nonetheless structured. ${ }^{3}$

By the r89os, photographic images of young Mediterranean male bodies began to encourage traffic to the south. Figure I was made into postcards by Wilhelm von Gloeden, a Prussian nobleman who had settled in the Sicilian town of Taormina. It broadly invokes ancient Greece (always in the background of the educated European imagination of male-male sex). The combination of fantasy and political economy extends into the present in what we now call, somewhat reductively, sex tourism.

Von Gloeden evidently had sexual relationships with many of his photographic models.

It is interesting to consider the manner in which that small Sicilian town dealt with the knowledge of Guglielmo Gloeden's sexual proclivities, for it is certain that many people knew of them ... It is noteworthy that some of his most constant supporters were the simplest women of the town: an egg seller, washer women, fish wives. A clue to this loyalty is found in a fact little known even to his close friends. Von Gloeden had not infrequently provided the dowries for the daughters of poor families whose suitors were young men of whom von Gloeden was fond. (Leslie 1977, 42-44)

The north-south interchange began well before the consolidation of the European idea of homosexuality. Thus in England in 1809 , after a spurt of hanging and pillorying of men accused of sodomy, Lord Byron set out on his first journey to Ottoman Greece. Enamored of both young men and women, Byron may have been drawn to Islamic lands by his reading of translations of Persian classical poets with similar attractions (Crompton 1985, III-29). Staying in a monastery in Athens, Byron developed a relationship with a young man, Niccolo Giraud, serious 
enough that he would include the latter, at one point, in his will (Crompton I985, I46-57). On his way home, Byron enrolled Giraud in a school on Malta, after which we lose track of this young man. Speaking Greek, Italian, and English, did Giraud become a successful businessman in a Mediterranean world pulled ever closer into the economic orbit of northern Europe?

Many others followed in Byron's steps: the Hanoverian lawyer Karl Heinrich Ulrichs, in many ways the world's first queer activist; ${ }^{4}$ perhaps the philosopher Friedrich Nietzsche (Köhler 2002); the British adventurer T.E. Lawrence; and a myriad of creative writers, including Oscar Wilde, André Gide, E. M. Forster, William Burroughs, and Joe Orton (Boone 2oI4; Aldrich 2003; Mullins 2002). In 1968, French philosopher Michel Foucault missed some of the iconic events of the uprising in Paris because he was living in Sidi Bou Saïd, teaching at the University of Tunis (Macey 1993, 18I-208).

Finally, Americans Paul and Jane Bowles settled in Tangier just after World War II. In anticipation of anthropologists' enthusiasm for collaborative ethnography after the I980s, Paul Bowles began transcribing stories from Moroccan men in the r96osmany his lovers-listing himself only as translator: Mohammed Mrabet's Love with a Few Hairs and Larbi Layachi's A Life Full of Holes both explore the interrelationship between European-Moroccan, male-male love and the local forms of male-female marriage that the former underwrote and made possible.

After two hundred years, much has changed in these interactions. As homosexual identity-and therefore heterosexuality-became more totalizing in the United States after World War II, many straight-identified men would no longer have sex with men, in any form. According to Hilderbrand (2013), gay travel from North America by the I970s was, to some 
extent, a search for foreign social scenes less affected by this cultural transformation, ones in which North American gay men could still have sex with straight men, "trade" they sometimes paid.

There were changes on the other side of the north/south interaction as well. By the early twentieth century, uncolonized Islamic lands like Persia, the elites of which had become intensely aware of Western repudiation of their sexual customs, quickly gave up long-established patterns of male-male love in their strivings to become "modern" (Najmabadi 2005). Apparently, nothing transforms sexual cultures as effectively as the mobilization of shame and embarrassment, ${ }^{5}$ so much so that now many in Islamic lands and sub-Saharan Africa know nothing of their same-sex sexual prehistories. ${ }^{6}$ As I have said, "homosexuality" is assumed by many in these areas to be a uniquely Western preoccupation.

In this essay, I take up the analysis of a case that continues older Mediterranean patterns but situates them in the different cultural context of Atlantic Africa after decolonization. A central part of European male fantasy that I have just described involved the attribution of extramasculinity to Sicilian and Arab men. But if so, African men were and continue to be doubly submitted to this regime, as Frantz Fanon argued years ago in Black Skin, White Masks ([1952] 2008).

In such a context, it is perhaps not surprising that the major streams of recent sex tourism to Africa have involved European women traveling south in search of African men (on such patterns in West Africa, see Ebron 1997; in East Africa, Meiu 2008, 2017). These interactions are now mediated not only by books and photographs but also by the Internet and its dating websites. And these more recent forms of communication have led 


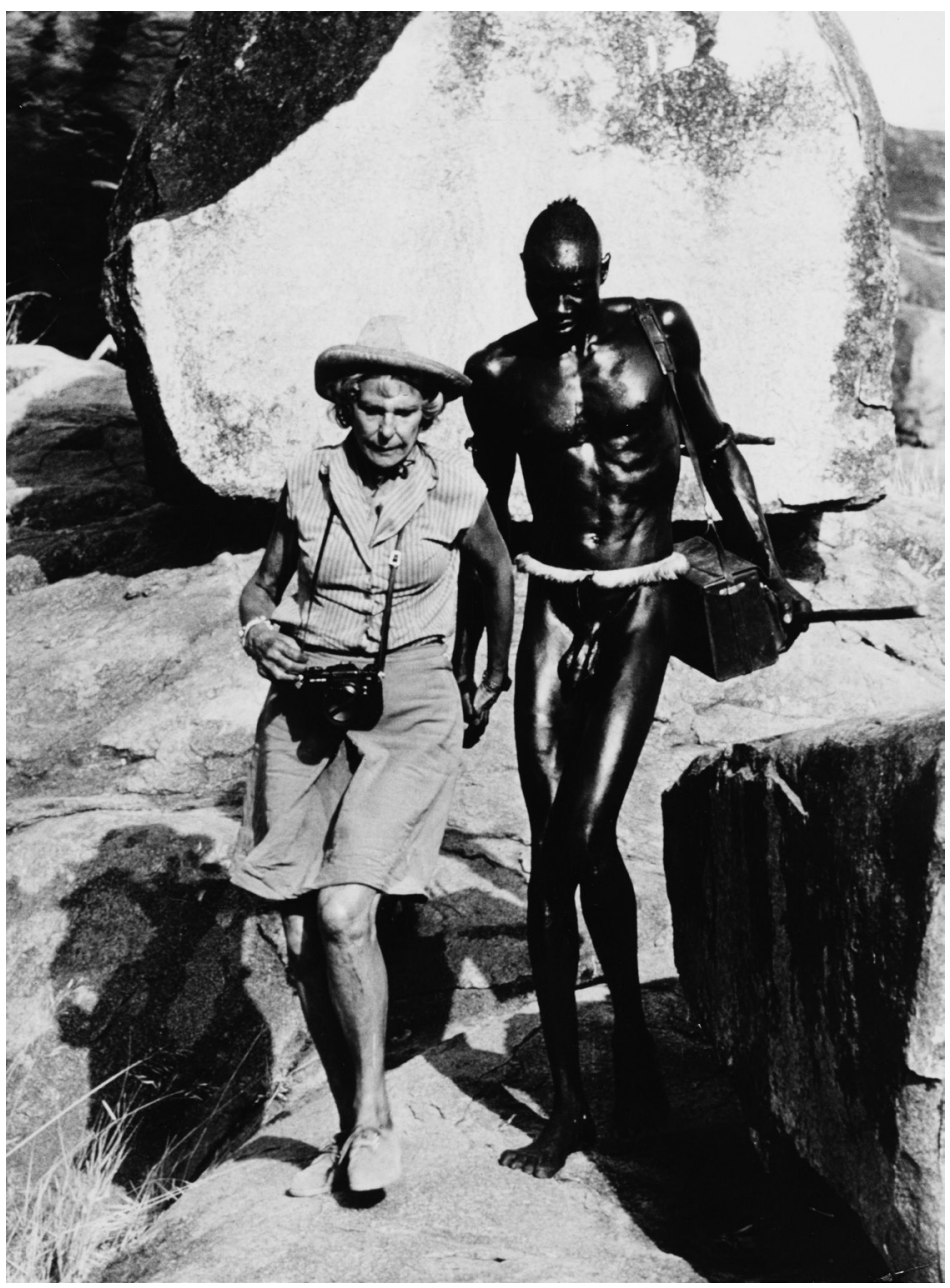

Figure 2. Leni Riefenstahl in the Nuba Mountains, courtesy of Getty Images (Keystone/Hulton Archive). 
to the explosion of what are now called romance scams. The FBI recently estimated that in 2015 alone such schemes netted more than \$200 million from North Americans?

But of course masculinity has also been an attraction for some European men. Without what Europeans regarded, and many still regard, as the civilizational attainments that Arabs had-a past tradition of monumental architecture, written languages, historical records, world religions-African men appeared closer to nature and therefore as enticingly, and sometimes threateningly, supersexed. When the memory of massive European enslavement of West African populations is added to this mix, an especially complex erotic field is created-as African American artist Kara Walker (1995), black British filmmaker Isaac Julien (1994), and black gay literary theorists like Robert Reid-Pharr (200I) and Darieck Scott (20I0) have begun to explore.

As I shall show below, sadomasochism or SM, a controversial practice within gay networks of the great Western cities after the I950s, became a part of the African scene I am going to describe. SM was, among other things, a quest for masculine styles. Ironically, the logic of racialization tended to place African men in the role of tops in SM fantasies. This inversion of the actual historical pattern-accompanied by the fantasy that the upending was motivated by black revenge for past white oppression — created a particular erotic experience for both Europeans and Africans. ${ }^{8}$ Inversely, when African men less frequently became servants or slaves in SM scenes, the historical verisimilitude must have added an edgy, dangerous frisson. Either way, there was no escaping history.

My focus is on, then, what I'm calling the erotics of history, how peculiar erotic attachments of individuals are conditioned 
by wider historical and cultural patterns and memories. For an extraordinarily well-documented example of this connectionand for an illustration of why such intimate details are usually so difficult to obtain-see Davidoff (1974, 1979). Davidoff describes the case of a late nineteenth-century English gentleman, Arthur Munby, who obsessively documented what we would now call a consensual SM relationship with a domestic maid, Hannah Cullwick, whom Munby secretly married (but with whom he never had sexual intercourse). Both Munby and Cullwick left diaries, photographs, and drawings that Munby willed to the archives of Trinity College, Cambridge. It was almost as if this documentation had become a fetish in itself. It recalled and reenacted sexual excitement. Following Anne McClintock's impressive Imperial Leather (1995), which reanalyzed the Munby-Cullwick case, especially in relation to colonial themes, I would like to situate stories of sexual attraction-fetishes-within the wider contours and changes of postcolonial capitalism itself. 9

To be able to accomplish that, I have found that I must reject a persistent conceptual move made over the last few decades involving what seems to me to be the attribution of an illusory power to the concept of sexuality: that is, that sexualities are consistent states of being, relatively stable forms of personhood, that stand behind and produce, cause, and organize erotic attachments. That the same person can, for example, feel quite different erotic attractions in different contexts, that social forces like peer pressure, both negative and positive, can be transformative, and that erotic commitments can change, sometimes significantly so-all these are elided. Despite the fluidity that results, the notion of sexuality seems somehow protected as an essence or a condition, whether it is thought to be biologically or culturally constituted. ${ }^{\circ}$ 
I am hardly the first to make this argument. Consider how far back the position I advocate goes, well before queer theory:"I "It would encourage clearer thinking on these matters if persons were not characterized as heterosexual or homosexual, but as individuals who have had certain amounts of heterosexual experience and certain amounts of homosexual experience. Instead of using these terms as substantives which stand for persons, or even as adjectives to describe persons, they may better be used to describe the nature of the overt sexual relations, or of the stimuli to which an individual erotically responds" (Kinsey, Pomeroy, and Martin 1948, 617). ${ }^{12}$

At one point, Kinsey et al. anticipated what is called labeling theory, developed by sociologists in the ig6os:

One of the factors that materially contributes to the development of exclusively homosexual histories, is the ostracism which society imposes upon one who is discovered to have had perhaps no more than a lone experience. The high school boy is likely to be expelled from school and, if it is in a small town, he is almost certain to be driven from the community. His chances of making heterosexual contacts are tremendously reduced after the public disclosure, and he is forced into the company of other homosexual individuals among whom he finally develops an exclusively homosexual pattern for himself. (Kinsey, Pomeroy, and Martin 1948, quoted in Plummer 198I, 17-I8)

The opposition between heterosexuality and homosexuality critiqued by Kinsey et al. depends fundamentally on the categorical oppositions created when the biological reproduction of human beings is assumed as a master teleology-heterosexual versus homosexual, straight versus queer, the second term being always the assumed reproductive failure. 
The problem is that nonreproductive sex seems universally present in human societies, is institutionalized in many cases, and is even celebrated in a few. And its presence may be, I shall suggest, currently increasing. Of course, biological reproduction must be effected at some level for societies and cultures to persist. But with respect to any particular society, this reproduction does not have to occur through biological means (see Paul 2015 for examples). The teleology, if there is one, is social and cultural reproduction-processes that can, in fact, contradict genetic evolutionary logic. ${ }^{13}$ I would argue, then, that we begin to think of the erotic as establishing the attractions required by sociality itself - one by-product of which can be biological reproduction. ${ }^{14}$

Without biological reproduction as the master teleology, the separation of object choice-from any number of other possibilities when it comes to the erotic-no longer makes sense. Now the question becomes, what is it about cultural definitions and individual and group memories that underlie what have been called fetishes that makes sex sexy?

Given my argument, wouldn't it be clarifying to throw out the entire apparatus of sexuality? The problem with such a move is that some social actors themselves, "homosexuals," decades after Kinsey, took it up. Jeffrey Weeks has written about how the early gay liberation movement of the rg6os was soon eclipsed by a different emphasis: "the breakdown of roles, identities, and fixed expectations' [advocated in early liberationists] was replaced by 'the acceptance of homosexuality as a minority experience,' an acceptance that 'deliberately emphasizes the ghettoization of homosexual experience and by implication fails to interrogate the inevitability of heterosexuality'" (Weeks, quoted in Bersani 1987, 203, n.8). 
This struggle in the West made homosexuals, and homosexuals made the struggle. That this movement has been successful in many ways (and that it should be welcomed in some respects) ${ }^{15}$ should not distract from the fact that it has also made it more difficult to understand erotics. It has helped to reinforce the notion that erotics is the outcome of so-called sexualities.

The struggle for homosexual rights succeeded, after all, not because object choice was different from any of the other sexual fetishes. Rather, it was successful, I would contend, because, after the legalization of abortion and the widespread availability of reliable chemically based birth control in the United States, the trope of biological reproduction no longer culturally singularized and underwrote heterosexual relationships. Why couldn't "homosexuals" enjoy the same (nonreproductive) rights?

But the division of everyone into heterosexuals and homosexuals tended to obscure the other sexual fetishes. Now, it was simply assumed that it is the sex of an object that arouses. But is it? Or is it, say, race, color, wealth, language accent, lower-class style, hair color, smell, being dressed in a leather jacket or a fur coat, masculinity, femininity, penetrating another body, being penetrated, and so on and so on, apparently ad infinitum?

What, then, is a fetish? I use the concept in two ways. The first, made famous by Marx and Freud-what I would call the modernist version - argues that a fetish somehow misrepresents "reality." It attributes a power to something that objectively it does not have. But if we eliminate the assumed teleology of biological reproduction (or socialist revolution), another version of the fetish emerges, one I shall call postmodern: that is, the simple description of social actors' own experience of an attraction that they cannot fully explain, that overpowers and "subjects" 
an individual otherwise considered "free" and autonomous. Postmodern fetishes just are.

The difference between these two versions is often a matter of perspective. The modernist version is typically attributed to others, not to oneself, while the postmodern version invariably rests within the bounds of an actor's own view (which, of course, may be "explained" otherwise by a modernist). I use both, according to context, in this essay.

Science studies theorist Bruno Latour (2010) has recently taken up the concept of the fetish in ways that overlap and differ with my exposition. ${ }^{16}$ His concept of antifetishism corresponds exactly with my definition of the modernist fetish, while his notion of the "factish" resembles, in some ways, my version of the postmodern fetish. Where I differ from Latour is the inconsistency with which he rejects modernism. According to him, the modernist fetish must always be a mistake, and in We Have Never Been Modern ([199I] 1993), he goes to some length to level the playing field between scientists and others as producers of knowledge. But in Reassembling the Social (2005), he takes the diametrically opposed position of arguing, in a classic modernist move, that his social theory trumps all others, especially "critical sociology." I believe, in contrast, that contradictory theories can coexist in both the natural and social sciences-in this case, the notions of the modernist and postmodern fetish.

Both Latour's and my expositions are inspired by the remarkable work of William Pietz, who pointed out that all notions of the fetish originated along the coast of Atlantic Africa, in the interaction of European traders and Africans after the fifteenth century. In what follows, I propose to bring a sense of the longue durée of Atlantic African history to analyze interactions 
mediated now by the Internet between African men and gay Europeans. ${ }^{17}$

In the Western metanarrative, men and women in capitalist societies have progressively constructed themselves in terms of "free" wage labor, in opposition to all forms of bound labor-with slavery at the limit. And with regard to political organization, "free" societies are said to require democracy, in which all citizens supposedly participate as equals. Finally, "free" trade and the untrammeled Internet of images and messages have created a density of global interaction that has brought the peoples of the four continents into a new intimacy (Lowe 2015).

However, participating in such freedoms has always required a particular kind of modern personhood - the lack of which has justified social exclusions (Povinelli 2006). Modern persons are assumed to have an interiority in which deliberative reason, rationality, is used to fashion and create the self. So Western liberalism not only exists in relation to an assumed nonmodern outside but also constantly fights an internal battle. As Albert Hirschman (1977) put it, rational "interests" exist in tension with what are assumed to be the "passions" in Western political and economic theory.

What Hirschman did not emphasize is that sex constitutes perhaps the prime passion for Westerners. The notion of the sexual fetish originated precisely in structural opposition to the tamed interests, and in doing so, it became the very epitome of the irrational. Perhaps it is not surprising, then, that the erotic for Westerners has often involved reversals, what we might call the abjection of rationality. In this context, the transgression of law, the assumed primary location of rationality in the West, can become erotic in itself. No more apposite illustration exists than 
the writings of the Marquis de Sade (carried out, incidentally, during that explosion of supposed reason, the French Revolution). The erotic extends, then, far beyond the question of the sex of an object. But this broader territory has hardly been explored in recent anthropology and history; ironically, nineteenth-century sexology seems to have been much more in touch with this variety-even if a large part of it was interpreted as perversion.

There are a great many quandaries to be faced on this broadened terrain. Perhaps the central one is the difference between power grounded in everyday social life (one might say Marx's or Foucault's kinds of power) and another sort embodied in fantasies and erotic fetishes-as in Freud's and, later, Lacan's exploration of their patients' imagination of the human body, its orifices and appendages, its social openings and closings. These two forms of power may intermesh and reinforce one another but, just as often, they may not. Any such connection has to be demonstrated, not simply assumed (and it is mostly assumptions that we have been given so far).

In her clarifying account of recent work on sex and gender, Janet Halley offers the following typology:

A person framing a conceptual, descriptive, normative, and/or political project that involves a discontinuity between two theories of power, two descriptions of the world, two normative aims, two invoked constituencies, and so on ... can choose between converging and diverging them. We could, for instance, decide that normatively it would be terrible to have a theory of homosexuality that was not ultimately feminist, or a feminism that did not wholly encompass our theory of homosexuality; we would then be aiming for complete convergence. Or we could say that it is better for some reason to have some division or autonomy or even conflict between the two projects; we would then be aiming for some degree of divergence. (Halley 2006, 25) 
My account is divergentist. There has been a persistent tendency in recent accounts of so-called sex tourism and more widely in some forms of feminism and postcolonialism ${ }^{18}$ to take up a convergentist approach that reads fantasies and representations as ipso facto evidence of exploitation. For example, literary critic Joseph Boone (1995, 90), to whom I owe much in this essay, wrote of the "occidental mode of male perception, appropriation, and control." But texts are not lives. Forms of sociality cannot be "read off" texts. In the example I shall analyze below, Atlantic African men reveled in the sexual and racial stereotypes that Europeans brought to their encounters. Europeans' fetishes, in African contexts, put Africans in control.

Many Westerners are disturbed by the very recognition of sexual fetishes (other than their own, of course, which they tend not to recognize as such). Fetishes, after all, transgress the Western notion of love. The desired is seemingly reduced only to a partial and inconsequential part of himself or herself - feet or hair, breasts or penis, age or race. Such partialisms are thought to "other" the beloved. But Freud and Lacan had more complex views of love, and indeed, the power of their theories lies in the ability to make sense of such ambivalence. As I shall argue, the very process of erotization may necessarily involve some "objectification."

Sharon Holland $(2012,46)$ writes, "I suggest that we can't have our erotic life — a desiring life-without involving ourselves in the messy terrain of racist practice." She poses Emmanuel Levinas's question, "Is the Desire for the Other (Autrui) an appetite or a generosity?" $(20 \mathrm{I} 2,4 \mathrm{I})$. I cannot answer that question for the people I shall describe. It requires a level of knowledge, finally, that I do not have. I would say, though, that the question arises in one cultural tradition (perhaps not all traditions, at least not in 
the same way) and, within that tradition, it should be raised with respect to all sexual relationships, not just culturally marked, cross-racial ones.

Grounded in history and anthropology (Traub 20I3), what follows reflects a wider, interdisciplinary investigation. In some ways, I return to the nineteenth-century sexologists for inspiration. And I hope to show that situations described by literary theorist Mary Louise Pratt (2008) as "contact zones," frontiers in which sexual and other cultural systems come into association, contradiction, and sometimes surprising interdependence, furnish especially rich contexts in which to think the erotic more broadly-my ultimate goal. 


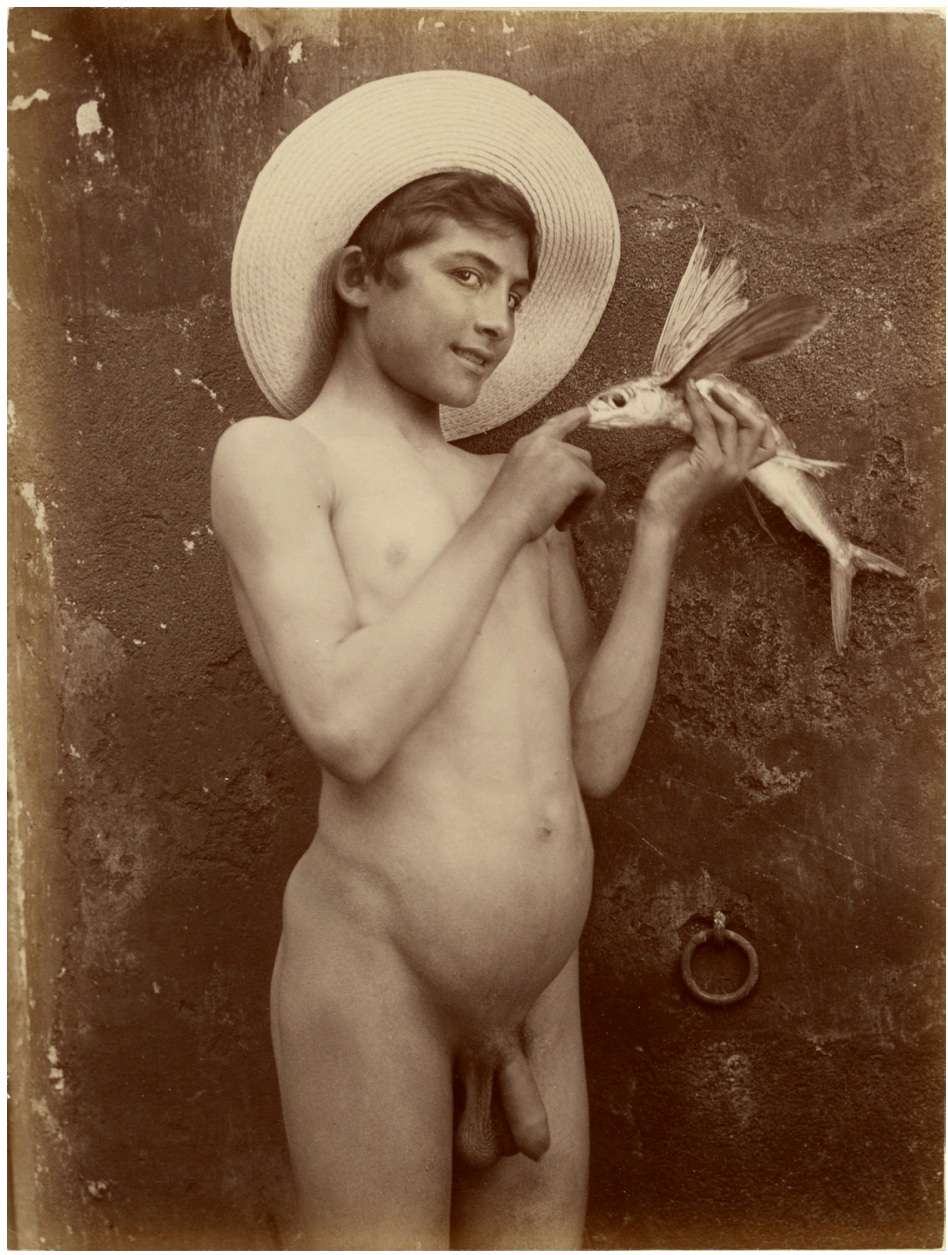

Figure 3. Ragazzo con pesce volante (Boy with a Flying Fish), by Baron Wilhelm von Gloeden, c. I895, courtesy of the J. Paul Getty Museum, Los Angeles. 